\title{
Children's Perspectives on Cyberbullying: Insights Based on Participatory Research
}

\author{
Niels Baas, MSc, Menno D.T. de Jong, PhD, and Constance H.C. Drossaert, PhD²
}

\begin{abstract}
Cyberbullying is an emerging problem among youngsters. Although the current body of knowledge about cyberbullying is expanding rapidly, it lacks a more in-depth research approach honoring adolescents' perspectives on the problem. Moreover, very few studies have focused on cyberbullying among elementary school children. The purpose of this study therefore, was to explore children's perspectives on the problem of cyberbullying. A participatory research design was used in which 28 children (aged 11-12 from four elementary schools) actively participated for 6 weeks in weekly scheduled group sessions. In these sessions, different aspects of cyberbullying were discussed using various enabling techniques. Between sessions, the children were given preparation assignments. The research revealed several ambiguities that should be addressed in interventions against cyberbullying. First, it appears difficult for all parties involved to distinguish cyberbullying from innocent pranks. Frequency and intention are key variables, but these are ambiguous in the context of cyberbullying. Second, cyberbullies may have very different motives, not all of which have to do with their relationship with the victim. Third, the expectations children have of the way their parents or teachers will react to incidents of cyberbullying are an obstacle for seeking help. Children are particularly afraid of overreaction and the subsequent loss of their Internet privileges. These results confirm earlier insights from research on cyberbullying, and examine the ambiguities in more detail. In addition, the research demonstrates the usefulness of participatory research to investigate cyberbullying among younger children and demonstrates that the research led to mutual learning.
\end{abstract}

\section{Introduction}

C YBERBULlying is A RELATIVELy NEW, but emerging phenomenon among youngsters. ${ }^{1,2}$ It is defined as "the use of information and communication technologies to support deliberate, repeated, and hostile behavior by an individual or group, that is intended to harm others. ${ }^{\prime 3}$ Table 1 summarizes common types of cyberbullying. ${ }^{1}$ Studies into the prevalence of cyberbullying show that 30 percent or more of the adolescents are victimized., ${ }^{1,2}$ Three characteristics differentiate (cyber)bullying from innocent pranks: intention, repetition, and power imbalance. ${ }^{4,5}$ However, previous research suggests that these criteria may not be as clear for cyberbullying as they are for traditional ways of bullying. ${ }^{6}$

Several studies have focused on differences between cyberbullying and traditional schoolyard bullying. ${ }^{1,4,7-10}$ The main differences ascertained, underline the potential harmfulness and threatening nature of cyberbullying, which can be more anonymous, more pervasive (reaching victims not only in school, but also at home), has a larger potential audience, and is less visible for adults in the victims' environment. Research shows that cyberbullying may have serious consequences, including sadness, frustration, anger, self-doubting, self-blaming, and behavioral problems. ${ }^{11-15}$

Cyberbullying may be part of social positioning processes in schools. ${ }^{14}$ It may be proactive-bullying to reach certain goals (e.g., a struggle for status, power, or friends)-or reactive-bullying as a reaction to (perceived) provocation or deviance. ${ }^{5,14}$ What is more, bullies often seem to choose victims who are different or deviant in some way. ${ }^{14}$ In general, research shows that cyberbullies have less empathic skills than their peers. ${ }^{16,17}$

Much of the current knowledge on cyberbullying is based on quantitative research ${ }^{18}$ typically obtained by use of questionnaires. $1,7,8,12$ Prestructured quantitative research has the advantage of enabling the experiences of many adolescents to be studied. However, it is less suitable for the exploration of more in-depth experiences and when one wishes to consider the problem from the perspective of adolescents themselves. Several researchers argue that qualitative research is essential 
Table 1. Types of Cyberbullying ${ }^{1}$

\begin{tabular}{cc}
$\begin{array}{l}\text { Category } \\
\text { of cyberbullying }\end{array}$ & \multicolumn{1}{c}{ Description } \\
\hline Flaming & $\begin{array}{c}\text { Sending angry, rude, vulgar messages } \\
\text { about a person to an online group } \\
\text { or to that person via e-mail or other text } \\
\text { messaging. }\end{array}$ \\
$\begin{array}{c}\text { Repeatedly sending offensive messages } \\
\text { via e-mail or other text messaging } \\
\text { harassment } \\
\text { to a person. }\end{array}$ \\
$\begin{array}{c}\text { Online harassment that includes threats } \\
\text { of harm or is excessively intimidating. } \\
\text { penigrations/ }\end{array}$ & $\begin{array}{c}\text { Sending harmful, untrue, or cruel } \\
\text { statements about a person to other people } \\
\text { or posting such material online. }\end{array}$ \\
Masquerading & $\begin{array}{c}\text { Pretending to be someone else and sending } \\
\text { or posting material that makes that } \\
\text { person look bad. }\end{array}$ \\
Outing & $\begin{array}{c}\text { Sending or posting material about a person } \\
\text { that contains sensitive, private, or } \\
\text { embarrassing information, including } \\
\text { forwarding private messages or images. }\end{array}$ \\
Excluding & $\begin{array}{c}\text { Cruelly excluding someone from an online } \\
\text { group. }\end{array}$ \\
\hline
\end{tabular}

for truly understanding children's well-being; furthermore, they assert the notion that children are perfectly capable of expressing themselves. ${ }^{19-23}$ Some studies adopted a qualitative approach by conducting focus groups or interviews. $5,9,10,15,18,23,24$ The available qualitative studies rely on single encounters between a researcher and participating children. With a topic as complex and personal as cyberbullying, however, it is dubitable whether one encounter would suffice in getting to the core of the problem. More time and repeated encounters may be needed to explore all relevant aspects, in particular, in the case of complex and ambiguous phenomena. In addition, such an approach may be used to build a relation of trust between the researcher and participants. ${ }^{22,25,26}$

A recommended approach that would enable children to explore the problem of cyberbullying from their own perspectives is participatory research. ${ }^{27-30}$ In participatory research, participants are treated as experts about their own lives, capable of defining, exploring, and often solving their own problems. Participants are enabled to shape the structure of the discussions, while the researcher acts as a mere facilitator. ${ }^{31-33}$ As such, participatory research aims at mutual learning and empowerment. The researcher learns about the participants, at the same time the research itself endows participants with problem-solving strategies (including empathy). ${ }^{29,31,32}$

Since the signing of the United Nations Convention on the Rights of the Child (UNCRC) in1989, a participatory research approach, focused on children's participation, has been developed. ${ }^{19,34}$ This approach has been used to study children's views on city planning, ${ }^{34}$ as well as the problems of street children. ${ }^{35}$ Several researchers have proposed guidelines for participatory research with children: ${ }^{19,20,36}$

- The research topic must be relevant and understandable for the children.
- Children must have the continuous opportunity to prepare their own viewpoints.

- Children's opinions must be taken seriously and explicitly acknowledged.

- Participation must be voluntary.

- Children must have the possibility to quit the research at any time.

In this article, we report on a participatory research-based study on elementary school children's perspectives concerning cyberbullying. Our goal was to explore the problem of cyberbullying and its ambiguities among 11-12-year-old children. Although this age group already actively uses the Internet, ${ }^{37,38}$ their perceptions on and experiences with cyberbullying have been largely neglected in the literature. Specifically, our research focused on four themes regarding cyberbullying-(a) incidence and impact, (b) differentiating cyberbullying from innocent pranks, (c) motives of bullies, and $(\mathrm{d})$ counteracting cyberbullying-and one methodological theme, evaluating empowerment of the participants.

\section{Method}

\section{Participants}

In total, 28 children (aged 11-12) from four elementary schools participated for 6 weeks. In every school, a group of seven children was formed with a similar number of boys and girls (15 vs. 13). The (first) author briefly presented the research to the participating classes; thereafter, children could express their willingness to participate. In all classes, nearly all children were enthusiastic. Of those willing to participate, a random selection of boys and girls was made by the teachers. An informing letter, asking for the parents' approval was sent to the parents. In the first meeting, the children were given more extensive information about the research, asked whether they were still willing to participate, and reminded of the possibility to quit the project at any time. All children participated enthusiastically until the end of the project. To make sure that enthusiastic classmates who did not participate could provide their input, a mailbox was placed in the classrooms. Many children posted ideas and experiences in it; these were subsequently discussed in the sessions.

\section{Procedure}

To actively engage the participants, we gave them the role of junior researchers. Six weekly meetings of approximately 1 hour were held in each school. Each session had a specific topic (see Table 2), but the children were free to decide which aspects of it would be discussed. The research was framed as a project aimed at creating an informative poster for peers. In the last session, the children completed an evaluation questionnaire.

The researcher's role was limited to facilitating discussion, managing group dynamics, and keeping track of time. In the sessions, several enabling techniques were used: the children were allowed to do drawings, write and recite stories or poems, clip examples from magazines, and use a flip-over chart. Groups also proposed and used other resources to express their opinions or gather information. For example, one group used the school's phone to collect information. All sessions were audio recorded (with the children's permission). The schools provided appropriate rooms for the sessions. 
Table 2. Overview of the Six Research Sessions

\begin{tabular}{|c|c|c|c|}
\hline & Meeting & Content discussed & Preparation \\
\hline 1 & Introduction & $\begin{array}{l}\text { Introduction of the research. Discussion of } \\
\text { behavioral rules (e.g., no blaming, listening to } \\
\text { each other, not using real names of people } \\
\text { involved in incidents). Instructions for using } \\
\text { the Junior Researcher's Diary. }\end{array}$ & - \\
\hline 2 & $\begin{array}{l}\text { Defining } \\
\text { cyberbullying }\end{array}$ & $\begin{array}{l}\text { Defining cyberbullying and behaviors that can } \\
\text { or cannot be defined as such. The boundary } \\
\text { between cyberbullying and innocent } \\
\text { cyberpranks. }\end{array}$ & $\begin{array}{l}\text { Creating word-webs (cyberbullying } \\
\text { associations): } \\
\text { - What is cyberbullying? } \\
\text { - What is not cyberbullying? }\end{array}$ \\
\hline 3 & $\begin{array}{l}\text { Bullies } \\
\text { and victims }\end{array}$ & $\begin{array}{l}\text { Describing characteristics of typical cyberbullies } \\
\text { and victims (without mentioning actual } \\
\text { bullies and victims). }\end{array}$ & $\begin{array}{l}\text { Drawing, collage, or magazine clipping: } \\
\text { - Visualize a typical cyberbully } \\
\text { - Visualize a typical victim }\end{array}$ \\
\hline 4 & $\begin{array}{l}\text { Prevention } \\
\quad \text { of cyberbullying }\end{array}$ & $\begin{array}{l}\text { Identifying relevant actors and their roles in } \\
\text { preventing cyberbullying from happening. }\end{array}$ & $\begin{array}{l}\text { Listing actors and roles: } \\
\text { - Assign possible roles to predefined actors } \\
\text { - Identify complementary actors and roles }\end{array}$ \\
\hline 5 & $\begin{array}{l}\text { Ceasing } \\
\text { cyberbullying }\end{array}$ & $\begin{array}{l}\text { Identifying relevant actors and their roles in } \\
\text { ceasing cyberbullying. }\end{array}$ & $\begin{array}{l}\text { Top } 3 \text { and scenario: } \\
\text { - Top } 3 \text { people-to discuss the problem with } \\
\text { - Top } 3 \text { people-who can solve the problem } \\
\text { - Scenario: A best friend is cyberbullied. What } \\
\text { would you recommend him/her to make it } \\
\text { stop? }\end{array}$ \\
\hline 6 & Conclusion & $\begin{array}{l}\text { Creating and presenting an informative poster } \\
\text { for peers.Evaluating the research project }\end{array}$ & $\begin{array}{l}\text { Create a top } 10 \text { of topics that should absolutely } \\
\text { be present on the informative poster. }\end{array}$ \\
\hline
\end{tabular}

In between sessions, the children made preparation assignments, which were provided in the first session in a Junior Researcher's Diary. The assignments provided a basis for the children to form their opinions about the topics that would be discussed. Moreover, the children were encouraged to speak with other children or adults about cyberbullying and to make their own observations when using the Internet. These experiences could be recorded in the Diary on Note Sheets. The children were explicitly told not to seek information in online encyclopedias or wikis, as these were probably created by adults. They were asked not to discuss their preparation materials with each other outside of the sessions.

Some procedural measures were taken to ensure the validity and reliability of the results. During the sessions, the facilitator made sure that any ambiguities were clarified in the discussions, and at the end of every session, the group was asked to summarize the main issues addressed using a flip-over chart. At the beginning of every new session, children had the opportunity to revisit previous sessions and add further context to or adjust earlier statements.

\section{Analysis}

All sessions were transcribed. The analysis focused on five main themes: (a) incidence and impact of cyberbullying, (b) differentiating cyberbullying from innocent pranks, (c) motives of bullies, (d) counteracting cyberbullying, and (e) empowerment. Within themes, the transcripts were analyzed using the principles of Grounded Theory. ${ }^{39}$ A coding scheme, enabling the data to speak, was gradually created based on the information in the transcripts. The transcripts were divided into fragments (each addressing one specific issue). The qualitative analysis program Atlas.ti was used to connect fragments to the categories in the coding scheme.

\section{Results}

\section{Incidence and impact of cyberbullying}

Cyberbullying appeared to be a common phenomenon in all four schools. Almost all participants had been confronted with cyberbullying, as a witness, victim, or bully. Half of the children had been victimized, and five reported having cyberbullied someone else. Although based on a small sample, our findings indicate that cyberbullying may already be considered a problem in this young age group. Most of the incidents that were reported involved name calling, threats, the sending of sexually explicit or disturbing content, and hacking each other's social network or e-mail accounts (see Table 3).

According to the children, cyberbullying may have a large impact on victims. Fear was one of the often mentioned effects. The fear of possible escalations to physical violence appeared to be even stronger than the fear of cyberbullying itself. As a result, victims were afraid to go to school. The anonymity of the bully was one of the most frightening features. A loss of trust in friends and classmates was another: anyone could be the anonymous bully ("I was bullied for a long time several years ago; online and offline. Eventually I found out that one of the bullies actually was my best friend, this got me really upset"). Other notable effects included sadness, emotional pain, and a decline of self-confidence.

Cyberbullying incidents may have drastic effects on children. Two girls actually witnessed this from nearby. Via a Dutch online community they met a girl who had been ceaselessly cyberbullied. In a cry for help, the girl had posted an online message in which she hinted at committing suicide. The bullies reacted with statements such as "Finally" and "Please do" and posted the cry for help on the Website's general message board. The girl eventually committed suicide. 
Table 3. Most Mentioned Actions Labeled as Forms of Online Bullying

\begin{tabular}{ll}
\hline Threatening & $\begin{array}{c}\text { Sending threatening mails or text } \\
\text { messages (sometimes death threats) } \\
\text { Accessing someone's e-mail, instant } \\
\text { messaging, or social network } \\
\text { profile account }\end{array}$ \\
Masquerading & $\begin{array}{c}\text { Sending messages using someone } \\
\text { else's identity } \\
\text { Publicly making fun of someone (e.g., } \\
\text { creating a Facebook account called } \\
\text { "stupid-sarah.com" and sharing } \\
\text { it with others) } \\
\text { Calling someone (funny or offending) } \\
\text { names } \\
\text { Scolding } \\
\text { Discriminating } \\
\text { Slighting or insulting someone } \\
\text { on the basis of ethnicity or } \\
\text { (presumed) sexual orientation } \\
\text { Encouraging someone to do adverse } \\
\text { things in school (and get punishment) } \\
\text { Following and harassing someone } \\
\text { constantly and/or everywhere online } \\
\text { Bullying random people on the Internet, } \\
\text { for no particular reason, mostly out } \\
\text { of boredom and based on superficial } \\
\text { cues (e.g., a profile picture) }\end{array}$ \\
Random bullying &
\end{tabular}

All of the above-mentioned incidents and effects were based on own experiences. However, it also became clear that the children were already aware of a broader spectrum of cyberbullying activities, such as provoking girls to undress in front of the webcam, or luring girls to one's house to rape them. Although examples like these were often mentioned and discussed vividly, it appeared that the children had no direct or indirect experience with them.

\section{Differentiating between cyberbullying and innocent pranks}

A potential problem regarding cyberbullying is that it may be hard to differentiate between cyberbullying and innocent pranks. Two important characteristics of cyberbullying emerged from the discussions, repetition and intention. According to the children, one-time occurrences would be bearable and not directly a form of cyberbullying ("Just a couple of pranks is not so bad, it can even be funny. But if it happens more often, it is not nice anymore."). Even more important, according to the children, are the presumed bully's intentions: they only speak of cyberbullying when the bully has harmful intentions. The discussions made clear that both characteristics are often ambiguous to children.

Although repetition is quite clear in traditional bullying, online one-time actions may have repetitive effects. An example mentioned was that a video is posted on YouTube and watched by many viewers. Bullies may not be aware of the lasting consequences of one-time actions.

The problem with intention is that it is a subjective notion, with potential problems of interpretation for both victims and bullies. Victims experience difficulties in estimating the intentions of the presumed bully ("It may be a joke for you, but how does the other child know it's a joke? It's only a nice joke when he knows it's one."). Presumed bullies do not always seem to consider the effects of their actions ("I hacked my friend's MSN account for fun. He was at home sitting at his computer saying 'Sh*t, sh*t, sh*t, I can't log on anymore'. He calls me in panic saying his computer has been hacked. And then I say: 'Joke'!").

The discussions among children showed that it is harder for those directly involved than for outsiders to estimate the intentions of a presumed bully or the possible impact on a victim. Some children had sent content to others that they had earlier described as cyberbullying. In their situations, however, the actions were justified as "just a joke." Examples of innocent actions mentioned were calling someone a ridiculous name (e.g., "stupid pancake"), hacking out of self-interest (e.g., stealing someone's credits), fake fights, criticizing someone, name-calling followed by a smiley, death threats in online shooting games, and continuously sending invitation messages.

An extra complication, according to the children, is that parents cannot adequately judge the severity of online actions ("Sometimes I call my friend funny names on MSN. Names like stupid, asshole, dumbass. When my mom sees this she punishes me. That is so annoying because it's just a joke and she can't understand that.").

\section{Motives of bullies}

According to the children, cyberbullies may have very different motives, which may further complicate the interpretation of cyberbullying incidents. Three categories of motives were mentioned; these may be combined. The first is an internally felt drive to cyberbully. Children may bully other children out of boredom, for pleasure, to reduce stress, or to compensate for being (cyber)bullied themselves. Trying to fit in, or trying to belong was another motive that was often mentioned ("You have to bully someone to prevent getting picked on yourself"). The second category is based on negative experiences with the victim, such as a row, jealousy, or the breaking up of a friendship or relationship. The third category is based on characteristics of the victim ("He is so ugly. Of course he gets cyberbullied."). This may involve appearance (e.g., clothes, wearing glasses, acne, skin color, out of the ordinary); socially related characteristics (name, friends, presumed sexual orientation, out of the ordinary); and personality (shy, insecure, kind-hearted, scared, boring). Bullies seem to prefer harassing children who are different and/or have less social or physical power.

\section{Thresholds for seeking help}

When children are victimized they find it hard to ask for help. A reason for their reluctance is because they feel ashamed of being bullied. Two aspects of these feelings of shame were mentioned. First, it is hard for children to admit being disliked by their peers, which would harm their selfimage and the image others have of them ("I wouldn't tell my mom. I am to ashamed to tell her that I am being bullied"). Second, victims may at least feel partially responsible for the bullying because they were the ones who decided to be online. They were often discouraged by their parents or caregivers to go online in the first place and expect reactions like "I told you so."

Another reason for not seeking help is that victims may be afraid of the consequences. The obstacle to talking to their teacher involves the fear of group discussions about their problems, which may have adverse effects ("You're afraid 
other children hear about it and start bullying you as well."). The obstacle to going to their parents or caregivers involves the fear of ill-considered actions like contacting the teacher, the bully, or the bully's parents ("My mother will immediately contact my teacher or the bully's parents, and that's something I really don't want.") or the fear of being called a mummy's boy. Moreover, they are afraid of losing their Internet connection if they tell their parents ("Taking the Internet away is one of the worst punishments there is. Even a bully would not deserve that. It is better to take a beating from all of your classmates than to be isolated from the Internet."). Having Internet access appears to be a necessity of life ("Losing your Internet connection is like losing your soul.").

\section{Empowerment}

During and after the sessions, various aspects of empowerment became clear. First, the project created awareness of the problem of cyberbullying among the participants, not only regarding its prevalence, but also regarding the impact ("Cyberbullying is a meaner way of bullying because you can hurt someone from the inside"). Children who trivialized the impact of cyberbullying were confronted with opposite opinions of their peers, who tried to get them to empathize more with victims. This approach appeared successful because eventually all children expressed they were against cyberbullying and almost all children $(N=22)$ stated that they would intervene if a cyberbullying incident would occur in their surroundings. All groups felt the urge to create anticyberbullying materials for peers. One group made an educational video, and the other groups created posters or logos, including claims like "Cyberbullying is mean and it is not cool." Several children also suggested that they could give lectures or create reports for school. So the project made a positive contribution to the children's attitude and behavioral intentions. In addition, the questionnaire showed that the children were very confident about their knowledge of cyberbullying: 25 out of 28 children stated that they would know what to do if they were cyberbullied - (the other three were hesitant). In the last session, one girl suggested that it would be a good idea for the government to hire her in the future as a cyberbullying consultant.

\section{Discussion}

The results of our study suggest that cyberbullying may already be a common problem among elementary school children. All sessions showed that cyberbullying is more than an incidental phenomenon in this age group. The children were very aware of the impact cyberbullying may have on victims. In addition to the incidents that the children experienced or witnessed in their immediate environment, they appeared to already know a broader gamut of (criminal) cyberbullying activities from the world of older adolescents and adults.

The main conclusion that can be drawn from our study is that there are several ambiguities that need to be addressed in terms of developing interventions aimed at preventing or counteracting cyberbullying. First, the results show that there is no clear line between cyberbullying and innocent pranks. Presumed bullies tend not to empathize with the victim and may underestimate the effects of their actions, which they primarily see as innocent pranks or harmless jokes. Victims may find it hard to estimate the presumed bully's intentions, and therefore are more likely to interpret intended jokes as forms of cyberbullying. From both perspectives, it appears that cyberbullying is more ambiguous than offline forms of bullying. Real cyberbullies, with harmful intentions, may use this ambiguity to laugh away the seriousness of their actions. Interventions to prevent cyberbullying should incorporate teaching children about the limitations of online communication as well as training them to empathize with the way their messages may be perceived.

Second, the results also show that cyberbullies may have very different motives, several of which have nothing to do with their relationship to the victim. It appears that there are children who simply feel an urge to cyberbully, for instance, to feel better or to reduce stress, or who bully to belong to a group. As an effect, they choose a vulnerable victim, which in their eyes may be anyone who is weaker or different. It may be a pitfall to exclusively focus on the relationship between bully and victim when trying to prevent cyberbullying.

A third ambiguity involves children's expectations of what will happen if they seek help from adults (parents, caregivers, or teachers) when they are victimized. Generally, they are afraid that the situation may only get worse, mainly because of adults over-reacting or taking away their online privileges. Interventions for lowering the threshold should focus on creating a safe haven in the home and school context. Despite the potential dangers of children's use of the Internet, parents, caregivers, and teachers should be more appreciative and understanding about the role the Internet plays in the social life of children. They should make explicit that they are aware that children may sometimes unintentionally have negative online experiences, that they are always available for guidance or support, that they will not take any action without the children's consent and, above all, that they will not take away their online privileges.

Methodologically, our study showed that participatory research is a feasible and fruitful approach for this particular age group. Work within all four groups led to detailed and rich data, which, on the level of the six main findings presented in this article, clearly converged. Moreover, the project led to empowerment of the children: they improved their knowledge and showed preventive attitudes and behaviors.

\section{Author Disclosure Statement}

No competing financial interests exist.

\section{References}

1. Li Q. Bullying in the new playground: research into cyberbullying and cyber victimization. Australian Journal of Educational Technology 2007; 23:435-454.

2. Mason KL. Cyberbullying: a preliminary assessment for school personnel. Psychology in the Schools 2008; 45:323-348.

3. Besley B. Cyberbullying. Available at www.cyberbullying.ca (accessed Nov. 22, 2011).

4. Wang J, Iannotti RJ, Nansel TR. School bullying among adolescents in the United States: physical, verbal, relational and cyber. Journal of Adolescence Health 2009; 45:368-375.

5. Law DM, Shapka JD, Domene JF, Gagné MH. Are cyberbullies really bullies? An investigation of reactive and proactive online aggression. Computers in Human Behavior 2012; 28:664-672. 
6. Langos C. Cyberbullying: the challenge to define. Cyberpsychology, Behavior, and Social Networking 2012; 15:285-289.

7. Slonje R, Smith PK. Cyberbullying: another main type of bullying? Scandinavian Journal of Psychology 2008; 49: 147-154.

8. Juvonen J, Gross EF. Extending the school grounds? Bullying experiences in cyberspace. Journal of School Health 2008; 78:496-505.

9. Vandebosch H, Van Cleemput K. Defining cyberbullying: a qualitative research into the perceptions of youngsters. CyberPsychology and Behavior 2008; 11:499-503.

10. Agatston PW, Kowalski R, Limber S. Students' perspectives on cyberbullying. Journal of Adolescent Health 2007; 41:59-60.

11. David-Ferdon C, Feldman M. Electronic media, violence and adolescents: an emerging public health problem. Journal of Adolescent Health 2007; 41:S1-S5.

12. Topçu Ç, Erdur-Baker Ö, Çapa-Aydin Y. Examination of cyberbullying experiences among Turkish students from different school types. CyberPsychology and Behavior 2008; 11:643-648.

13. Diamanduros T, Downs E, Jenkins SJ. The role of school psychologists in the assessment, prevention and intervention of cyberbullying. Psychology in the Schools 2008; 45:693-704.

14. Thornberg R. 'She's weird!'-the social construction of bullying in schools: a review of qualitative research. Child Society 2011; 25:258-267.

15. Parris L, Varjas K, Meyers J, Cutts H. High school students' perceptions of coping with cyberbullying. Youth and Society 2011; 1-23. Available at: http://yas.sagepub.com/content/ early/2011/03/06/0044118X11398881.abstract (accessed Apr. 24, 2012).

16. Renati R, Berrone C, Zanetti MA. Morally disengaged and unempathic: do cyberbullies fit these definitions? An exploratory study. Cyberpsychology, Behavior, and Social Networking 2012; 15:391-398.

17. Steffgen G, König A, Pfetsch J, Melzer A. Are cyberbullies less empathic? Adolescents' cyberbullying behavior and empathic responsiveness. Cyberpsychology, Behavior, and Social Networking 2011; 14:643-648.

18. Houghton SJ, Nathan E, Taylor M. To bully or not to bully, that is not the question: Western Australian early adolescents' in search of a reputation. Journal of Adolescent Health 2012; 1-25. Available at: http://jar.sagepub.com/content/ early/2012/01/05/0743558411432638.abstract (accessed Apr. 27, 2012).

19. Hart R. (2008) Children's participation: the theory and practice of involving young citizens in community development and environmental care. Londen: Earthscan.

20. Lansdown G. (2000) Promoting children's participation in democratic decision-making. Florence: UNICEF Innocenti Research Center.

21. Pascal C, Bertram T. Listening to young citizens: the struggle to make real a participatory paradigm in research with young children. European Early Childhood Education Research Journal 2009; 17:249-262.

22. Punch $S$. Research with children: the same or different from research with adults? Childhood 2002; 9:321-341.

23. Mishna M, Saini M, Solomon S. Ongoing and online: children and youth's perceptions of cyberbullying. Children and Youth Services Review 2009; 31:1222-1228.
24. Smith PK, Mahdavi J, Carvalho M, et al. Cyberbullying: its nature and impact in secondary school pupils. Journal of Child Psychology and Psychiatry 2008; 49:376-385.

25. Bronfenbrenner U. (1979) The ecology of human development: experiments by nature and design. Cambridge, MA: Harvard University Press.

26. Almekinders C, Beukema L, Tromp C. (2008) Research in action: Theories and practices for innovation and social change. Wageningen: Wageningen Academic Publishers.

27. Cornwall A, Jewkes R. What is participatory research? Social Science and Medicine 1995; 41:1667-1676.

28. Lawlor D, Marsden C, Sanderson J, Simmonds D. Rapid participatory appraisal of young people's sexual health needs: an evaluation of meta-planning. Health Education Journal 1999; 58:228-232.

29. Brown CS, Lloyd S, Murray SA. Using consecutive rapid participatory appraisal studies to assess, facilitate and elevate health and social change in community settings. BMC Public Health 2006; 6:68.

30. Chambers R. The origins and practice of participatory rural appraisal. World Development 1994; 22:953-969.

31. Loader R, Amartya L. Participatory rural appraisal: extending the research methods base. Agricultural System 1999; 62:73-85.

32. Binns T, Hill T, Nel E. Learning from the people: participatory rural appraisal, geography and rural development in the "new" South Africa. Applied Geography 1997; 17: $1-9$.

33. Rifkin SB. Rapid rural appraisal: its use and value for health planners and managers. Public Administration 1996; 74: 509-526.

34. Malone K. Children, youth and sustainable cities. Local Environment 2001; 6:5-12.

35. Nieuwenhuys O. Action research with street children: a role for street educators. PLA Notes 1996; 25:52-55.

36. Davis JM. Understanding the meanings of children: a reflexive process. Child Society 1998; 12:325-335.

37. Van den Bulck J. Television viewing, computer game playing, and Internet use and self-reported time to bed and time out of bed in secondary-school children. Sleep 2004; 27:101-104.

38. De Bell M, Chapman C. Computer and Internet use by children and adolescents in 2001. Education Statistics Quarterly 2003; 5:7-11.

39. Glaser BG, Straws AL. (1967) The discovery of grounded theory: strategies for qualitative research. New York, NY: Aldline.

Address correspondence to: Niels Baas

Department of Communication Studies

Faculty of Behavioral Sciences

University of Twente Cubicus Building

P.O. Box 217

7500 AE Enschede The Netherlands

E-mail: n.baas@utwente.nl 